\title{
Pengaruh Dewan Komisaris, Komite Direksi dan Enterprise Risk Management Disclosure terhadap Nilai Perusahaan
}

\author{
Diani Lestari ${ }^{1}$ \\ Fakultas Ekonomi dan Bisnis \\ Universitas Mataram, Indonesia \\ Email: dianilestari.sntbv@gmail.com
}

\author{
Budi Santoso 2 \\ Fakultas Ekonomi dan Bisnis \\ Universitas Mataram, Indonesia
}

\section{Hermanto $^{3}$ \\ Fakultas Ekonomi dan Bisnis \\ Universitas Mataram, Indonesia}

\begin{abstract}
ABSTRAK
Penelitian ini menguji apakah terdapat pengaruh dewan komisa ris, komite manajemen risiko sebagai salah satu komite direksi dan pengungkapan enterprise risk management terhadap nilai perusahaan. Sampel penelitian yang digunakan adalah 31 perusahaan sektor keuangan yang terdaftar di Bursa Efek Indonesia periode 2016-2018. Teknik analisis data menggunakan analisis regresi data panel dengan random effect model. Hasil penelitian menunjukkan bahwa komite manajemen risiko berpengaruh negatif dan signifikan terhadap nilai perusahaan, sedangkan pengaruh dewan komisaris dan pengungkapan enterprise risk management tidak signifikan terhadap nilai perusahaan. Hasil penelitian ini dapat dijadikan bahan pertimbangan bagi manajemen perusahaan maupun regulator untuk mendorong pembentukan komite manajemen risiko untuk untuk penerapan manajemen risiko yang efektif.
\end{abstract}

Kata Kunci: Dewan komisaris; komite manajemen risiko; pengungkapan manajemen risiko perusahaan; nilai perusahaan.

\section{Effect Of Board Commisionaire, Board Of Director's Committee And Enterprise Risk Management Disclosure Towards Firm Value}

\section{ABSTRACT}

This research analyzes whether there is an effect of board commis sionaire, risk management committee as one of board od director's committee and enterprise risk management disclosure towards firm value. The sample of this research is 31 financial companies listed in Indonesia Stock Ex change for the period 2016-2018. Regression analysis of panel data with the random-effect model was applied to analyze the data. The results show the risk management committee has a negative and significant effect on the firm value, whereas the effect board of commissionaire and enterp rise risk management disclosure towards firm value does not significant. The result of this research is can be used as a consideration for the management and the regulator to encourage companies to established risk management committees for effective implementation risk management.

Keywords: $\quad$ Board OfCommissionaire; Risk Management Committee; Enterprise Risk Management Disclosure; Firm Value.

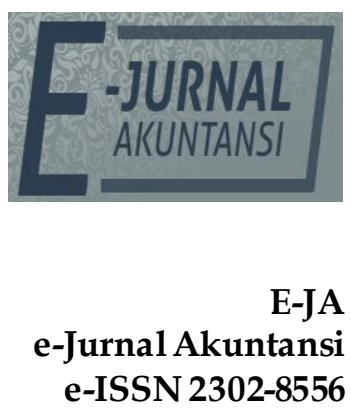

Vol. 30 No. 4

Denpasar, April 2020

Hal. 945-957

Artikel Masuk: 8 Januari 2020

Tanggal Diterima: 17 April 2020 


\section{PENDAHULUAN}

Pesatnya perkembangan ekonomi dan teknologi saat ini berdampak pada meningkatnya risiko-risiko yang dihadapi entitas bisnis yang dapat mempengaruhi kelangsungan hidup perusahaan. Salah satu kasus kebangkrutan yang berdampak pada perekonomian global adalah kebangkrutan Lehman Brothers, dimana sebelum pengumuman kepailitannya merupakan Bank Investasi terbesar keempat di Amerika. Nilai assetnya juga melampaui asset kasus kebangkrutan sebelumnya yaitu Enron \& WorldCom. Selain kasus kebangkrutan, terdapat juga kasus fraud oleh pihak internal perusahaan seperti kasus fraud pengadaan pesawat dan mesin pesawat oleh Direktur Utama PT. Garuda Indonesia, Tbk (BBC Indonesia, 2017), kasus fraud laporan keuangan oleh perusahaan industri farmasi PT. Kimia Farma, Tbk, serta kasus pencucian uang dan penggelapan dana nasabah oleh relations manager Citibank.

Kasus-kasus diatas menunjukkan pentingnya penerapan manajemen risiko perusahaan. Penerapan manajemen risiko dapat meningkatkan kinerja perusahaan, mengurangi risiko financial distress, serta respon negatif pasar modal (Florio \& Leoni, 2017). Pemerintah dan industri terlibat untuk menerjemahkan manajemen risiko terintegrasi kedalam praktik dan memperbaiki kemampuan perusahaan dalam mengelola risiko. Perhatian pemerintah pada praktik manajemen risiko meningkat pada beberapa tahun terakhir, terutama pada sektor keuangan. Hal tersebut dapat dilihat dari penerbitan Peraturan Bank Indonesia Nomor 11/25/PBI/2009 tentang Perubahan atas Peraturan Bank Indonesia Nomor 5/8/PBI/2003 tentang Penerapan Manajemen Risiko (Bank Indonesia, 2009), Peraturan Otoritas Jasa Keuangan Nomor 18 / POJK.03 / 2016 tentang penerapan manajemen risiko bagi bank umum (Otoritas Jasa Keuangan, 2016), Peraturan Otoritas Jasa Keuangan No.1/POJK.05/2015 tentang penerapan manajemen risiko bagi lembaga jasa keuangan non-bank (Otoritas Jasa Keuangan, 2015).

Selain penerapan manajemen risiko, sebagai wujud transparansi perusahaan juga dituntut untuk mengungkapkan kepada publik bagaimana perusahaan mengelola risiko-risiko yang dihadapi. Berdasarkan Keputusan Bapepam LK Nomor KEP-431/BL.2012 pengungkapan penerapan manajemen risiko perusahaan publik dalam annual report sudah bersifat mandatory. Hasil penelitian Devi et al. (2017) menunjukkan pengungkapan enterprise risk management dalam annual report dapat menjadi strategi untuk peningkatan nilai perusahaan. Namun, Baxter et al.(2013) menyatakan kualitas enterprise risk management berpengaruh positif dan signifikan terhadap nilai perusahaan hany a pada saat krisis keuangan.

Berdasarkan agency theory Jensen \& Meckling, (1976) internal monitoring diperlukan didalam struktur tata kelola agar agent (manajemen) bertindak sesuai kepentingan pemilik modal (principal). Dewan komisaris merupakan organ tata kelola yang berfungsi mengawasi operasional perusahaan agar sesuai dengan tujuan perusahaan. Keberadaan komite-komite dibawah direksi dan komisaris dapat meningkatkan akuntabilitas dewan dan pelaksanaan tugas yang lebih efektif. Komite manajemen risiko merupakan salah satu komite direksi yang bertugas menentukan strategi manajemen risiko perusahaan dan mengevaluasi proses implementasi manajemen risiko. Beasley et al (2005) mengemukakan 
bahwa pengangkatan chief risk officer (CRO) berpengaruh positif pada reaksi pasar modal pada perusahaan non keuangan, tapi tidak pada perusahaan keuangan. Baxter et al. (2013) menyatakan bahwa kualitas enterprise risk management berpengaruh positif pada nilai perusahaan tapi hanya pada saat krisis keuangan.

Inkonsistensi hasil penelitian di atas menjadi dasar untuk menganalisis apakah terdapat pengaruh dewan komisaris, komite manajemen risiko dan pengungkapan enterprise risk management terhadap nilai perusahaan.

Agency theory merupakan hubungan antara agent (manajemen) dan principal (pemilik modal). Hubungan antara agent (manajemen) dengan principal sangat memungkinkan terjadinya konflik keagenan. Permasalahan keagenan ditandai dengan adanya perbedaan kepentingan dan informasi yang tidak lengkap (asimetri informasi) antara pihak principal dan pihak agent Jensen \& Meckling, (1976). Untuk mengatasi konflik kepentingan tersebut, diperlukan adanya pengawasan internal oleh dewan komisaris dan komite audit (Fama \& Jensen, 1983), pengawasan dari pemegang saham mayoritas (Shleifer \& Vishny, 1997), adanya pengendalian internal Matsumura \& Tucker, (1992), serta pengawasan eksternal melalui audit laporan keuangan perusahaan oleh auditor eksternal (Watts \& Zimmerman, 1986). Enterprise risk management juga dianggap sebagai salah satu bagian yang penting dalam struktur tata kelola perusahaan sejak adanya beberapa kasus fraud laporan keuangan serta kasus kebagkrutan (Desender, et al, 2007).

Signalling theory (Spence, 2002) menggambarkan perilaku dua pihak yang memiliki akses berbeda terhadap suatu informasi. Dalam konteks perusahaan, pihak internal perusahaan (insider) lebih memahami real quality dari perusahaan dibanding pihak eksternal (outsider) sehingga muncul asimetri informasi. Untuk mengurangi asimetri informasi tersebut perusahaan mengungkapkan laporan keuangan serta pelaksanaan tata kelola perusahaan melalui laporan tahunan. Pengungkapan enterprise risk management merupakan bagian dari laporan pelaksanaan tata kelola perusahaan yang baik dimana perusahaan memberikan informasi mengenai risiko-risiko yang dihadapi perusahaan dan bagaimana risiko tersebut dikelola agar tidak menghambat pencapaian tujuan perusahaan.

Manajemen risiko perusahaan (enterprise risk management) telah dijadikan sebagai strategi yang digunakan untuk mempertahankan kelangsungan hid up perusahaan (going concern), mempertahankan kinerja dan tingkat profitabilitas perusahaan. Menurut Committee of Sponsoring Organization of Treadway Commission (2004) manajemen risiko merupakan suatu proses yang dipengaruhi board of director, manajemen dan staf lainnya, yang diimplementasikan dalam setiap strategi perusahaan dan dirancang untuk mengidentifikasi kejadian potensial yang dapat mempengaruhi perusahaan dan mengelola risiko sesuai dengan risk appetite untuk memberikan keyakinan memadai dalam pencapaian tujuan perusahaan. Jadi, penerapan manajemen risiko mengharuskan adanya proses identifikasi, pengukuran, pengendalian dan pemantauan risiko pada setiap kegiatan perusahaan.

Menurut perspektif agency theory, adanya pendelegasian wewenang dari principal (pemilik modal) ke agen (management) dapat menimbulkan konflik kepentingan karna baik principal maupun agen akan berusaha untuk 
memaksimalkan tingkat utilitas yang diharapkannya. Untuk mengurangi konflik kepentingan tersebut diperlukan pengawasan agar agen bertindak sesuai harapan principal. Dewan komisaris berperan menjalankan fungsi pengawasan atas operasional perusahaan termasuk penerapan manajemen risiko yang efektif. Ukuran dewan komisaris yang kecil akan berpengaruh positif pada kinerja dewan, namun dapat berpengaruh negatif apabila ukuran dewan tersebut terlalu besar (Meizarohn \& Lucyanda, 2011).

Jumlah anggota dewan komisaris dapat mempengaruhi kualitas pengawasan terhadap manajemen perusahaan yang dapat berdampak pada pengurangan masalah keagenan dan berpotensi merugikan perusahaan. Hasil penelitian Asante-Darko et al. (2018) menunjukkan pengaruh ukuran dewan komisaris tidak signifikan terhadap nilai perusahaan sedangkan hasil penelitian Isshaq et al (2009) dan Mishra \& Kapil (2018) menyatakan ukuran dewan komisaris berpengaruh positif dan signifikan terhadap nilai perusahaan. Hasil penelitian Manurung \& Kusumah (2016) juga menunjukkan ukuran dewan berpengaruh positif terhadap enterprise risk management.

$\mathrm{H}_{1}$ : Dewan komisaris berpengaruh positif terhadap nilai perusahaan.

Keberadaan komisaris independen dapat meningkatkan kualitas pengawasan karena tidak terafiliasi dengan perusahaan yang dapat mempegaruhi pengambilan keputusan. Perusahaan dengan proporsi komisaris independen yang lebih tinggi akan lebih memperhatikan risiko perusahaan dibandingkan proporsi komisaris independen yang rendah (O'Sullivan, 1997). Manurung \& Kusumah (2016) menyatakan komisaris independen berpengaruh positif terhadap enterprise risk management. Hasil penelitian Mishra \& Kapil (2018) menunjukkan komisaris independen berpengaruh positif dan signifikan terhadap kinerja keuangan perusahaan.

$\mathrm{H}_{2}$ : Komisaris independen berpengaruh positif terhadap nilai perusahaan.

Penerapan manajemen risiko memerlukan adanya infrastruktur organisasi manajemen risiko sesuai dengan kebutuhan dan jenis-jenis risiko yang dihadapi. Komite risiko adalah bagian struktur organisasi manajemen risiko setingkat direksi yang bertugas menetapkan kebijakan dan strategi penerapan manajemen rIsiko untuk perusahaan secara menyeluruh (Komite Nasional Kebijakan Governance, 2012).

Fungsi komite manajemen risiko akan lebih efektif dengan partisipasi anggota komite. Frekuensi rapat komite menunjukkan upaya komite dalam memenuhi tugas dan tanggung jawabnya. Keberadaan komite risiko dan penunjukan chief risk officer berpengaruh positif dan signifikan terhadap nilai perusahaan (Florio \& Leoni, 2017). Krause \& Tse, (2016) menyatakan risk management berguna untuk penciptaan nilai perusahaan, mengurangi biaya modal dan mengurangi potensi financial distress.

$\mathrm{H}_{3}$ : Komite manajemen risiko berpengaruh positif terhadap nilai perusahaan.

Pengungkapan enterprise risk management merupakan informasi mengenai profil risiko perusahaan dan dampaknya terhadap perusahaan serta ba gaimana perusahaan mengelola risiko tersebut untuk pencapaian tujuan perusahaan. Pengungkapan ERM berdampak positif terhadap persepsi pelaku pasar (Baxter et al., 2013). Perusahaan dengan shopisticated ERM lebih profitable dan dinilai lebih baik oleh pasar. Perusahaan dengan ERM yang belum sempurna atau tidak 
memiliki system ERM kurang profitable dan kurang diapresiasi oleh investor (Florio \& Leoni, 2017). Konsisten dengan hal tersebut, hasil penelitian memberikan Abdullah et al. (2015), Devi et al. (2017), Sanjaya \& Linaw ati (2015) memberikan bukti empiris dimana pengungkapan enterprise risk management berpengaruh positif dan signifikan terhadap nilai perusahaan.

$\mathrm{H}_{4}$ : Pengungkapan enterprise risk management berpengaruh positif terhadap nilai perusahaan.

\section{METODE PENELITIAN}

Penelitian ini menggunakan pendekatan kuantitatif dan jenis penelitian yang digunakan adalah penelitian assosiatif dengan hubungan kausal. Populasi dalam penelitian ini adalah perusahaan keuangan yang terdaftar di Bursa Efek Indonesia dengan waktu penelitian meliputi tahun 2016-2018 yang datanya diperoleh melalui situs resmi BEI di www.idx.co.id dan website resmi masingmasing perusahaan. Dari hasil purposive sampling diperoleh 31 perusahaan yang memenuhi kriteria sampel.

Tabel 1. Kriteria Pengambilan Sampel

\begin{tabular}{ll}
\hline \multicolumn{1}{c}{ Kriteria Pengambilan Sampel } & Jumlah \\
\hline Perusahaan keuangan terdaftar di BEI & 74 \\
Perusahaan keuangan yang belum terdaftar per1 Januari 2016 & $(5)$ \\
& \\
Perusahaan yang mengalami delisting & $(2)$ \\
Perusahaan dengan data tidak lengkap & $(12)$ \\
Perusahaan yang belum membentuk komite manajemen risiko & $(24)$ \\
& \\
Jumlah perusahaan yang menjadi sampel & 31 \\
Jumlah observasi selama3 tahun & 93 \\
\hline
\end{tabular}
Sumber: Data Penelitian, 2019

Variabel dependen dalam penelitian ini adalah Nilai Perusahaan (Y) sedangkan variabel independen adalah dewan komisaris $\left(X_{1}\right)$; komisaris independen $\left(X_{2}\right)$; komite manajemen risiko $\left(X_{3}\right)$ dan pengungkapan enterprise risk management $\left(\mathrm{X}_{4}\right)$.

Rasio keuangan yang dapat digunakan untuk mengukur nilai pasar perusahaan adalah Tobin's $Q$.

Tobin's $Q=\frac{M V S+D}{T A}$.

Keterangan:

Tobin's $Q \quad$ : Nilai perusahaan

MVS : Nilai pasar saham

D : Nilai buku hutang

TA : Nilai buku total aset perusahaan

Ukuran Dewan Komisaris (X1), merupakan perbandingan jumlah anggota dewan komisaris dengan direksi. Jumlah anggota dewan komisaris setidaknya harus lebih besar atau paling tidak sama direksi.

Komisaris Independen yaitu jumlah komisaris independen dibandingkan dengan jumlah seluruh anggota dewan komisaris. Komite Nasional Kebijakan Governance (2006) mendefinisikan komisaris independen sebagai komisaris yang 
tidak berasal dari pihak terafiliasi. Meizaroh \& Lucyanda (2011) berpendapat bahwa proporsi anggota independen dalam dewan komisaris dikatakan sebagai indikator independensi dewan.

Keefektifan kinerja komite manajemen risiko dapat dipengaruhi oleh frekuensi rapat, frekuensi rapat yang tinggi diasumsikan dapat menghasilkan monitoring yang lebih baik. Dalam penelitian ini, komite manajemen risiko diukur dengan menjumlahkan rapat yang diselenggarakan selama satu tahun. Hal tersebut sesuai dengan penelitian Florio \& Leoni (2017), Ardiansyah \& Adnan (2014).

Pengungkapan ERM merupakan tingkat pengungkapan atas risiko-risiko yang telah dikelola perusahaan yang terdiri dari 108 item yang mencakup delapan dimensi yaitu: 1) lingkungan internal; 2) penetapan tujuan; 3) identifikasi kejadian; 4) penilaian risiko; 5) respons atas risiko; 6) kegiatan pengawasan; 7) informasi dan komunikasi; dan 8) pemantauan (Meizaroh dan Lucyanda, 2011). (Devi et al., 2017), dan (Meizaroh \& Lucyanda, 2011). Proksi yang digunakan untuk mengukur pengungkapan ERM adalah indeks ERM disclosure.

ERMDI = $\Sigma \mathrm{ij}$ Ditem $/ \Sigma \mathrm{ij}$ ADitem

Keterangan:

ERMDI : ERM Disclosure Index

Sij Ditem : Total skor item ERM yang diungkapkan

$\Sigma \mathrm{ij}$ ADitem : Total item ERM yang seharusnya diungkapkan

Model analisis yang digunakan dalam penelitian ini adalah regresi linear berganda. Hipotesis penelitian ini diuji dengan model sebagai berikut :

$Y=\alpha+\beta_{1} X_{1}+\beta_{2} X_{2}+\beta_{3} X_{3}+\beta_{4} X_{4}$ e.

\section{HASIL DAN PEMBAHASAN}

Hasil analisis statistik deskriptif menunjukkan bahwa firm value (Y) yang diukur dengan Tobin's $Q$ mencapai nilai maksimum sebesar 1,59 yang dicapai oleh Bank Central Asia, Tbk sedangkan nilai minimum sebesar 0,81 dicapai oleh Bank Bumi Artha, Tbk. Jika nilai Tobin's Q lebih besar dari 1 mengindikasikan bahwa pasar memberi nilai lebih terhadap perusahaan, sebaliknya jika nilai Tobin's $Q$ kurang dari atau sama dengan 1 berarti perusahaan tersebut dinilai kurang oleh pasar (undervalue).

Ukuran dewan komisaris $\left(X_{1}\right)$ yang diukur dengan jumlah dewan komisaris terhadap jumlah jumlah direksi memiliki nilai maksimum sebesar 1,2 dan nilai minimum sebesar 0,3. Nilai maksimum menunjukkan terdapat perusahaan yang jumlah dewan komisarisnya lebih besar dari jumlah direksi.

Proporsi Komisaris Independen $\left(X_{2}\right)$ yang diukur dengan jumlah komisaris independen dibagi dengan jumlah seluruh anggota dewan komisaris, memiliki nilai maksimum 1 dan nilai minimum 0,3. Nilai maksimum menunjukkan terdapat perusahaan yang seluruh anggota dewan komisarisnya merupakan komisaris independen sedangkan nilai minimum 0,3 menunjukkan semua perusahaan telah mematuhi peraturan OJK No. 33/POJK.04/2014 tentang direksi dan dewan komisaris emiten atau perusahaan publik yang mewajibkan jumlah komisaris independen minimal 30\% (tiga puluh persen) dari jumlah seluruh anggota dewan komisaris. 
Tabel 2. Hasil analisis Statistik Deskriptif

\begin{tabular}{llllll}
\hline & $\mathrm{Y}$ & $\mathrm{X} 1$ & $\mathrm{X} 2$ & $\mathrm{X} 3$ & $\mathrm{X} 4$ \\
\hline Mean & 1.075021 & 0.784907 & 0.562809 & 8.172043 & 0.799383 \\
Median & 1.030175 & 0.800000 & 0.500000 & 8.000000 & 0.814815 \\
Maximum & 1.593215 & 1.200000 & 1.000000 & 35.00000 & 0.962963 \\
Minimum & 0.812168 & 0.363636 & 0.333333 & 1.000000 & 0.500000 \\
Std. Dev. & 0.155116 & 0.183412 & 0.114976 & 5.466546 & 0.132462 \\
Skewness & 1.311281 & -0.166388 & 0.763659 & 1.956036 & -0.576184 \\
Kurtosis & 4.520995 & 2.540707 & 4.336503 & 9.291515 & 2.124643 \\
Observations & 93 & 93 & 93 & 93 & 93 \\
\hline
\end{tabular}

Sumber: Data Penelitian, 2019

Berdasarkan Tabel 2. komite manajemen risiko $\left(X_{3}\right)$ yang diukur dengan frekuensi pelaksanaan rapat dalam 1 tahun memiliki nilai maksimum sebesar 35 dan nilai minimum sebesar 1 . Nilai maksimum menunjukkan tingginya upaya komite manajemen risiko dalam pengelolaan risiko perusahaan serta mengevaluasi strategi dan kebijakan manajemen risiko yang sedang berjalan. Nilai minimum sebesar 1 menunjukkan komite manajemen risiko belum melaksanakan tugas dan tanggung jawabnya dengan maksimal.

Tabel 2. menunjukkan pengungkapan manajemen risiko perusahaan $\left(X_{4}\right)$ memiliki nilai maksimum sebesar 0,96 dan nilai minimum sebesar 0,50. Nilai maksimum menunjukkan terdapat perusahaan yang pengungkapan manajemen risiko dalam laporan tahunannya tinggi dan telah sesuai dengan rekomendasi Committee of Sponsoring Organization Treadway Commission (COSO), perusahaan tersebut adalah Bank BNI Tbk. Sedangkan nilai minimum menunjukkan tingkat pengungkapan manajemen risiko perusahaan yang rendah dan hanya memenuhi ketentuan regulasi. Perusahaan dengan nilai minimum adalah Bank Mega Tbk pada tahun 2016 dan Bank Pembangunan Daerah Banten Tbk pada tahun 2018.

Uji normalitas dalam penelitian ini menggunakan menggunakan uji Jarque Bera. Nilai Jarque Bera statistik mengikuti distribusi Chi Square dengan 2 df (degree of Freedom). Nilai Jarque Bera selanjutnya dihitung signifikansinya untuk menguji hipotesis berikut (Ghozali \& Ratmono, 2013;145).

$\mathrm{H}_{0}$ : Residual terdistribusi normal

$\mathrm{H}_{\mathrm{a}}$ : Residual tidak terdistribusi normal

Tabel 3. Hasil Uji Normalitas

\begin{tabular}{cc}
\hline Keterangan & Nilai \\
\hline Jarque Bera & 4,29 \\
Signifikansi & 0.12 \\
\hline
\end{tabular}

Sumber: Data Penelitian, 2019

Dari Tabel 3. dapat disimpulkan $\mathrm{H}_{0}$ yang menyatakan data terdistribusi normal dapat diterima.

Adanya multikolinieratas dapat dilihat dari korelasi antar variabel independen yang melebihi 0,80 (Ghozali \& Ratmono, 2013;73) . Berdasarkan matriks korelasi pada Tabel 4. tidak terdapat korelasi antar variabel independ en yang melebihi 0,80 sehingga dapat disimpulkan tidak terdapat multikoliniearitas antar variable independen. 
Tabel 4. Hasil Uji Multikolinieritas

\begin{tabular}{ccccc}
\hline & $\mathrm{X} 1$ & $\mathrm{X} 2$ & $\mathrm{X} 3$ & $\mathrm{X} 4$ \\
\hline $\mathrm{X} 1$ & 1.000000 & -0.308540 & -0.007397 & -0.043335 \\
X2 & -0.308540 & 1.000000 & 0.006901 & -0.115807 \\
X3 & -0.007397 & 0.006901 & 1.000000 & -0.011166 \\
X4 & -0.043335 & -0.115807 & -0.011166 & 1.000000 \\
\hline
\end{tabular}

Sumber: Data Penelitian, 2019

Untuk mendeteksi adanya heteroskedastisitas dalam penelitian ini dilakukan dengan Uji Glejser. Suatu data dapat dikatakan terbebas dari heteroskedastisitas apabila secara statistic variabel independen tidak signifikan mempengaruhi variable dependen nilai Absolut Ut (Abs Ut). Hal ini terlihat dari probabilititas signifikansinya diatas 5\% (Ghozali \& Ratmono, 2013;91). Dari hasil uji glejser mengindikasikan terdapat heteroskedastisitas.

Tabel 5. Hasil Uji Heteroskedastisitas

\begin{tabular}{lllll}
\hline \multicolumn{5}{c}{ Heteroskedasticity Test: Glejser } \\
\hline Variable & Coefficient & Std. Error & t-Statistic & Prob. \\
\hline $\mathrm{C}$ & 0.092897 & 0.009714 & 9.562853 & 0.0000 \\
$\mathrm{D}(\mathrm{X} 1)$ & 0.052782 & 0.051104 & 1.032836 & 0.3045 \\
$\mathrm{D}(\mathrm{X} 2)$ & -0.166163 & 0.096369 & -1.724229 & 0.0882 \\
$\mathrm{D}(\mathrm{X} 3)$ & -0.001053 & 0.001649 & -0.638196 & 0.5250 \\
$\mathrm{D}(\mathrm{X} 4)$ & 0.015292 & 0.080030 & 0.191081 & 0.8489 \\
\hline
\end{tabular}

Sumber: Data Penelitian, 2019

Tabel 5. menunjukkan semua variabel independen memiliki nilai probabilitas diatas $5 \%$ sehingga dapat disimpulkan data terbebas dari heteroskedasisitas.

Pengujian autokorelasi dalam penelitian ini menggunakan uji Langrage Multiplier (LM Test) atau disebut juga uji Breusch-Godfrey (BG Test). Hipotesis yang diajukan LM Test adalah :

$\mathrm{H}_{0}$ : tidak ada autokorelasi

$\mathrm{H}_{\mathrm{a}}$ : ada autokorelasi

Jika nilai $\mathrm{p}$ dari nilai Obs*R-Squared signifikan secara statistik (kurang dari 0,05) maka $\mathrm{H}_{0}$ (tidak ada autokorelasi) ditolak (Ghozali \& Ratmono, 2017, p. 127).

Tabel 6. Hasil Uji Autokorelasi

\begin{tabular}{lcll}
\hline \multicolumn{4}{c}{ Breusch-Godfrey Serial Correlation LM Test: } \\
\hline F-statistic & 2.718901 & Prob.F $(2,85)$ & 0.0717 \\
Obs*R-squared & 5.531732 & Prob.Chi-Square(2) & 0.0629 \\
\hline Sumber
\end{tabular}

Sumber: Data Penelitian, 2019

Tabel 6. menunjukkan nilai Obs*R-Squared tidak signifikan secara statistik (0,06 lebih besar dari 0,05) sehingga dapat disimpulkan $\mathrm{H}_{0}$ yang menyatakan tidak terdapat autokorelasi diterima.

Dalam regresi data panel sebelum melakukan uji hipotess diperlukan estimasi model antara common OLS model, fixed effect model atau random effect model yang paling sesuai dengan data penelitian. Setelah dilakukan Uji Redundant Fixed Effect dan Hausman Test diperoleh hasil bahwa Random Effect Model merupakan model terbaik untuk penelitian ini dibanding common OLS Model dan fixed effect model. Hasil regresi data panel dengan menggunakan random effect model 
menunjukkan bahwa nilai $\mathrm{F}$ sebesar 2,275 dengan signifikansi 0,03 lebih kecil dari 0,05 . Hasil tersebut mengindikasikan bahwa model regresi dinyatakan fit dan semua variabel independen berpengaruh secara simultan terhadap variabel dependen. Nilai Adjusted R Squared sebesar 0.069 menunjukkan bahwa varian dari variabel bebas mampu menjelaskan varian terikat sebesar $6,9 \%$ sisanya dijelaskan oleh variable lain yang tidak dicantumkan dalam model.

Tabel 7. Hasil Analisis Regresi Data Panel dengan Random Effect Model

\begin{tabular}{lclll}
\hline Variable & Coefficient & Std. Error & t-Statistic & Prob. \\
\hline C & 1.268958 & 0.169563 & 7.483697 & 0.0000 \\
X1 & -0.070855 & 0.074565 & -0.950242 & 0.3446 \\
X2 & -0.039240 & 0.119516 & -0.328324 & 0.7434 \\
X3 & -0.008679 & 0.002757 & -3.147785 & 0.0022 \\
X4 & -0.056683 & 0.145983 & -0.388288 & 0.6987 \\
\multicolumn{4}{l}{ Weighted Statistics } & \\
R-squared & 0.110229 & Mean dependent var & 0.31524 \\
AdjustedR-squared & 0.069785 & S.D. dependent var & 0.07381 \\
S.E. of regression & 0.071194 & Sumsquared resid & 0.44603 \\
F-statistic & 2.725470 & Durbin-Watsonstat & 1.37536 \\
Prob(F-statistic) & 0.034308 & & \\
\hline
\end{tabular}

Sumber: Data Penelitian, 2019

Berdasarkan hasil regresi pada Tabel 7. variabel ukuran dewan komisaris memiliki Nilai t hitung sebesar 0,95 lebih kecil dari nilai $t$ tabel sebesar 1,662 dan berarah negatif dengan tingkat signifikansi 0,34 lebih besar dari nilai $5 \%(0,74>$ $0,05)$ nilai probabilitas sebesar 0,34 atau lebih besar dari nilai signifikansi 0,05 dan nilai koefisien sebesar -0,07. Hal tersebut mengindikasikan pengaruh ukuran dewan komisaris terhadap nilai perusahaan tidak signifikan atau hipotesis pertama ditolak. Hasil penelitian ini sejalan dengan hasil penelitian Asante-Darko (2018) yang menyatakan tidak terdapat pengaruh signifikan ukuran dewan komisaris dengan nilai perusahaan. Namun, tidak konsisten dengan hasil penelitian Mishra \& Kapil (2018) yang menyatakan board size berpengaruh positif dan signifikan terhadap nilai perusahaan. Besarnya proporsi dewan komisaris dibandingkan dengan jumlah direksi tidak menjamin efektifitas pengawasan terhadap jalannya perusahaan. Berdasarkan agency theory keberadaan dewan komisaris diperlukan untuk memastikan agent (manajemen) bertindak sesuai kepentingan principal (pemilik modal dan stakeholder lainnya) dan mengurangi perilaku oportunis agent. Peraturan OJK juga mensyaratkan jumlah dewan komisaris tidak boleh lebih besar dari jumlah direksi.

Nilai t hitung komisaris independen terhadap nilai perusahaan sebesar 0,328 lebih kecil dari nilai $\mathrm{t}$ tabel sebesar 1,662 dan berarah negatif dengan tingkat signifikansi sebesar 0,74 lebih besar dari taraf signifikansi 0,05 d an nilai koefisien sebesar -0,039. Hasil penelitian ini mendukung hasil penelitian Mishra \& Kapil (2018) yang menunjukkan keberadaan komisaris independen hanya berpengaruh signifikan terhadap kinerja keuangan perusahaan saja (ROA) tapi tidak berpengaruh pada nilai pasar (Tobin'S Q). Ketentuan mengenai proporsi komisaris independen minimal 30\% pada tahun 2014 untuk perusahaan publik publik belum cukup tinggi bagi dewan komisaris untuk menjalankan fungsi pengawasan dan pemberian nasihat kepada direksi. Hal tersebut dapat dilihat dari ketentuan OJK terbaru pada tahun 2016 tentang Penerapan Tata Kelola Bagi 
Bank Umum yang mewajibkan proporsi komisaris independen minimal 50\% dari jumlah seluruh dewan komisaris. Agency theory mengusulkan adanya fungsi pengawasan dalam operasional perusahaan agar perusahaan beroperasi sesuai dengan tujuan perusahaan dan stakeholder lainnya dengan membentuk dewan komisaris. Untuk menunjang independensi dewan komisaris diperlukan adanya anggota dewan komisaris yang tidak memiliki hubungan keuangan, kepengurusan, kepemilikan saham dan atau hubungan keluarga dengan anggota direksi, komisaris dan pemegang saham pengendali yang dapat mempengaruhi kemampuan yang bersangkutan untuk bertindak independen yang disebut dengan komisaris independen. Keberadaan komisaris independen juga dapat menjamin terlaksananya salah satu prinsip tata kelola perusahaan yang baik (good corporate governance) yaitu indepensi.

Nilai t hitung komite manajemen risiko terhadap nilai perusahaan sebesar 3,147 lebih besar dari nilai $\mathrm{t}$ tabel sebesar 1,662 dengan tingkat signifikansi sebesar 0,002 lebih kecil dari nilai a $5 \%(0,002<0,05)$ dan nilai koefisien sebesar 0,008 . Hal tersebut menunjukkan komite manajemen risiko berpengaruh negat if dan signifikan terhadap nilai perusahaan. Tugas komite manajemen risiko adalah menetapkan kebijakan dan strategi penerapan risiko untuk perusahaan. Frekuensi rapat yang terlalu tinggi menunjukkan belum terdapat penerapan manajemen risiko yang efektif bagi perusahaan sehingga berpengaruh negatif terhadap nilai perusahaan. Tujuan pembentukan komite manajemen risiko adalah untuk membantu tugas direksi dan komisaris dalam penerapan risiko perusahaan yang efektif. Jika dikaitkan dengan agency theory keberadaan komite manajemen risiko adalah untuk membantu agent untuk meningkatkan nilai pemegang saham (principal).

Hasil penelitian ini konsisten dengan hasil penelitian Florio \& Leoni (2017) yang menyatakan keberadaan komite manajemen risiko dan penunjukan chief risk officer berpengaruh positif dan signifikan terhadap nilai perusahaan. Penerapan manajemen risiko dinilai dapat meningkatkan nilai perusahaan karena dapat membantu perusahaan dalam menghindari kerugian, kebangkrutan dan biaya reputasi.

Nilai $\mathrm{t}$ hitung pengungkapan enterprise risk management terhadap nilai perusahaan sebesar 0,388 lebih kecil dari t tabel sebesar 1,662 dan berarah negatif dengan tingkat signifikan sebesar 0,34 lebih besar dari nilai a $5 \%(0,34>0,05)$. Hal tersebut menunjukkan luasnya pengaruh pengungkapan manajemen risiko perusahaan tidak signifikan terhadap nilai perusahaan. Hasil penelitian ini tidak konsisten dengan hasil penelitian Devi, Budiasih dan Badera (2017) yang menyatakan pengungkapan ERM berpengaruh positif dan signifikan terhadap nilai perusahaan. Inkonsistensi hasil penelitian tersebut dikarenakan perbedaan objek penelitian dimana peneliti terdahulu menggunakan perusahaan manufaktur sebagai obyek penelitian sedangkan dalam penelitian ini menggunakan perusahaan sector keuangan. Tujuan pengungkapan ERM adalah untuk mengurangi asimetri informasi antara principal dan agent namun berdasarkan konsep signaling theory informasi yang berikan bisa dianggap sebagai good news atau bad news oleh penerima informasi. Dalam pengungkapan $E R M$ perusahaan tidak hanya dituntut untuk mengungkapkan prosedur pengelolaan risiko tapi juga profil risiko yang dihadapi perusahaan. Profil risiko 
adalah gambaran atau uraian dari suatu kelompok risiko yang berisikan risiko risiko yang terkait dengan perusahaan (Komite Nasional Kebijakan Governance, 2012). Pengungkapkan informasi tentang risiko terlalu detail memberikan dampak buruk pada nilai perusahaan dan tidak dapat mengimbangi efek positif dari pengurangan asimetri informasi (Martikainen et al. 2015).

\section{SIMPULAN}

Berdasarkan hasil analisis data, kesimpulan penelitian ini adalah komite manajemen risiko berpengaruh negatif dan signifikan terhadap nilai perusahaan, sedangkan pengaruh ukuran dewan komisaris, komisaris independen dan pengungkapan enterprise risk management tidak signifikan terhadap nilai perusahaan. Keberadaan komite manajemen risiko dalam struktur tata kelola perusahaan dapat dianggap sebagai sinyal positif oleh investor karna menunjukkan komitmen perusahaan dalam pengelolaan risiko-risiko yang dihadapi perusahaan dan berdampak pada nilai perusahaan namun frekuensi rapat yang terlalu tinggi menunjukkan perusahaan belum memiliki kebijakan dan strategi manajemen risiko yang efektif sehingga berpengaruh negative terhadap nilai perusahaan.

Hasil penelitian menunjukkan bahwa agency theory masih relevan digunakan untuk menjelaskan perilaku direksi (agent). Keberadaan komitekomite direksi dan komisaris penting untuk memastikan kepentingan semua stakeholder terpenuhi. Demikian juga dengan relevansi signaling theory dalam pelaporan annual report perusahaan, dimana tidak semua informasi yang diungkapkan dalam laporan tahunan dianggap sebagai good news yang dianggap sebagai sinyal positif oleh penerima informasi. Pengungkapan profil risiko pada perusahaan dengan risiko tinggi dapat dianggap sebagai sinyal negatif karna dapat menilai prospek perusahaan kedepannya. Hasil penelitian ini dapat dijadikan masukan bagi manajemen dan regulator untuk mendorong pembentukan komite manajemen risiko. Keterbatasan dalam penelitian ini adalah rendahnya nilai adjusted $r$ squared yang mengindikasikan variable dependen lebih banyak dipengaruhi oleh variable diluar model. Peneliti selanjutnya dapat menambah jumlah variable untuk menganalisis faktor lain yang dapat mempengaruhi nilai perusahaan.

\section{REFERENSI}

Abdullah, M., Abdul Shukor, Z., Mohamed, Z. M., \& Ahmad, A. (2015). Risk management disclosure: A study on the effect of voluntary risk management disclosure toward firm value. Journal of Applied Accounting Research, 16(3), 400-432.

Ardiansyah, L. O. M., \& Adnan, M. A. (2014). Faktor-Faktor yang Mempengaruhi Luas Pengungkapan Enterprise Risk Management. Jurnal Ekonomi, Manajemen Dan Akuntansi, 23(2), 89-105.

Asante-Darko, D., Adu Bonsu, B., Famiyeh, S., Kwarteng, A., \& Goka, Y. (2018). Governance structures, cash holdings and firm value on the Ghana Stock Exchange. Corporate Governance: The International Journal of Business in Society, 18(4), 671-685.

Bank Indonesia. Perubahan atas Peraturan Bank Indonesia Nomor 5/8/PBI/2003 
tentang Penerapan Manajemen Risiko, Pub. L. No. 11/25/PBI/2009 (2009). Indonesia.

Baxter, R., Hoitash, R., \& Yezegel, A. R. I. (2013). Enterprise Risk Management Program Quality : Determinants, Valur Relevance, and the Financial Crisis. Contemporary Account Research, 30, 1264-1295. https://doi.org/doi:10.1111/j.1911-3846.2012.01194.x

BBC Indonesia. (2017). Mantan Dirut Garuda Tersangka Kasus Korupsi. Retrieved February 7, 2018, from https://www.bbc.com/indonesia/dunia38674859

Beasley, M. S., Clune, R., \& Hermanson, D. R. (2005). Enterprise risk management: An empirical analysis of factors associated with the extent of implementation. Journal of Accounting and Public Policy, 24(6), 521-531.

Deegan, C. (2017). Twenty five years of social and environmental accounting research within Critical Perspectives of Accounting: Hits, misses and ways forward. Critical Perspectives on Accounting, 43, 65-87. https://doi.org/10.1016/j.cpa.2016.06.005

Desender, K., Barcelona, U. A. De, \& Bellaterra, C. (2007). On the Determinants of Enterprise Risk Management Implementation, 115-119.

Devi, S., Budiasih, I. G. N., \& Badera, I. D. N. (2017). Pengaruh Pengungkapan Enterprise Risk Management dan Pengungkapan Intellectual Capital terhadap Nilai Perusahaan. Jurnal Akuntansi Dan Keuangan Indonesia, 14(1), 20-45.

Fama, E. F., \& Jensen, M. C. (1983). Agency problems and residual claims. The Journal of Law and Economics, 26(2), 327-349.

Florio, C., \& Leoni, G. (2017). Enterprise risk management and fi rm performance : The Italian case. The British Accounting Review, 49(1), 56-74. https://doi.org/10.1016/j.bar.2016.08.003

Ghozali, I., \& Ratmono, D. (2017). Analisis Multivariat dan Ekonometrika dengan Eviews 10. Semarang: Badan Penerbit Universitas Diponegoro.

Isshaq, Z., Bokpin, G. A., \& Mensah Onumah, J. (2009). Corporate governance, ownership structure, cash holdings, and firm value on the Ghana Stock Exchange. The Journal of Risk Finance, 10(5), 488-499.

Jensen, M. C., \& Meckling, W. H. (1976). Theory of The Firm : Managerial Behavior, Agency Cost and Ownership Structure, 3, 305-360.

Komite Nasional Kebijakan Governance. (2012). PENERAPAN MANAJEMEN RISIKO BERBASIS GOVERNANCE, 1-91.

Krause, T. A., \& Tse, Y. (2016). Risk management and firm value: recent theory and evidence. International Journal of Accounting and Information Management, 24(1), 56-81.

Manurung, D. T. H., \& Kusumah, R. W. R. (2016). Telaah Enterprise Risk Management Melalui Corporate Governance dan Konsentrasi Kepemilikan, (204), 335-348. https://doi.org/10.18202/jamal.2016.12.7025

Martikainen, Minna; Kinnunen, Juha; Antti Miihkinen; Troberg, P. (2015). Article information: Journal of Aplied Accounting Research, 16(3), 333-358. https://doi.org/http://dx.doi.org/10.1108/JAAR-10-2014-0117

Matsumura, E. M., \& Tucker, R. R. (1992). Fraud detection: A theoretical foundation. The Accounting Review, 67(4), 753. 
Meizaroh; Lucyanda, J. (2011). Pengaruh Corporate Governance dan Konsentrasi Kepemilikan pada Pengungkapan Enterprise Risk Management, (Simposium Nasional Akuntansi XIV Aceh 2011), 21-22.

Mishra, R. K., \& Kapil, S. (2018). Effect of board characteristics on firm value: evidence from India. South Asian Journal of Business Studies, 7(1), 41-72.

O'Sullivan, N. (1997). Insuring the agents: The role of directors' and officers' insurance in corporate governance. Journal of Risk and Insurance, 545-556.

Otoritas Jasa Keuangan. Penerapan Manajemen Risiko bagi Lembaga Jasa Keuangan Non-Bank, Pub. L. No. No.1/POJK.05/2015 (2015).

Otoritas Jasa Keuangan. Penerapan Manajemen Risiko Bagi Bank Umum (2016).

Sanjaya, C. K., \& Linawati, N. (2015). Pengaruh Penerapan Enterprise Risk Management dan Variabel Kontrol Terhadap Nilai Perusahaan di Sektor Keuangan. Finesta, 3(1), 52-57.

Shleifer, A., \& Vishny, R. W. (1997). The limits of arbitrage. The Journal of Finance, 52(1), 35-55.

Spence, M. (2002). Signaling in retrospect and the informational structure of markets. American Economic Review, 92(3), 434-459.

Watts, R. L., \& Zimmerman, J. L. (1986). Positive accounting theory. Prentice-Hall Inc. 